\title{
EVALUASI WAKTU MENGGUNAKAN CRITICAL PATH METHOD (CPM) PADA PROYEK JALAN RABAT BETON DESA KAMELANTA
}

\author{
Ahmad Efendi 1), Romy Talanipa ${ }^{2)}$ \\ 1)S Prodi Teknik Sipil, Universitas Muhammadiyah Buton \\ 2) Prodi Teknik Sipil, Universitas Halu Oleo \\ Email: fahlan.efendi@gmail.com
}

\begin{abstract}
Abstrak
Tujuan penelitian ini adalah untuk mengetahui pengendalian manajemen waktu pada proyek jalan rabat beton Desa Kamelanta Kecamatan Kapontori Kabupaten Buton menggunakan metode network CPM (Critical Path Method). Hasil penelitian menunjukan bahwa (1) Total waktu penyelesaian pekerjaan proyek Jalan Rabat Beton di Desa Kamelanta Kecamatan Kapontori Kabupaten Buton adalah 10 minggu yang menunjukkan manajemen waktu proyek ini tidak terganggu serta pekerjaan sudah berjalan dengan baik; (2) Dengan Menggunakan metode CPM (Critical Path Method), proyek jalan rabat beton Desa Kamelanta Kecamatan Kapontori Kabupaten Buton dapat dipercepat waktu penyelesaiannya menjadi 9 minggu dengan cara aktivitas E (Galian Tanah), F (Pas. Batu Gunung), G (Pas. Batu Kosong), H (Urugan Batu 2/3) dan I (Rabat Beton) waktu pekerjaannya dilaksanakan bersamaan, sehinggah jalur kritis yang akan terbentuk pada pekerjaan ini adalah jalur $1-4-12-15$.
\end{abstract}

Kata kunci: evaluasi waktu, Critical Path Method (CPM), proyek jalan

\begin{abstract}
The purpose of this study was to determine the time management control of the concrete rebate road project in Kamelanta Village, Kapontori District, Buton District using the CPM (Critical Path Method) network method. The results showed that (1) The total time for completion of the Jalan Rabat Beton project work in Kamelanta Village, Kapontori District, Buton Regency was 10 weeks which showed that the time management of the project was not disturbed and the work had gone well; (2) Using the CPM (Critical Path Method) method, the concrete rebate road project in Kamelanta Village, Kapontori District, Buton Regency can be accelerated to 9 weeks by means of E (Land Excavation), F (Pas. Batu Gunung), G (Pas Batu Kosong), H (Urugan Batu 2/3) and I (Concrete Rebates) when the work is carried out together, so that the critical path that will be formed in this work is lines 1-4-12-15.
\end{abstract}

Keywords: time evaluation, Critical Path Method (CPM), road project 


\section{SANG PENCERAH}

Volume 5, Nomor 1, Februari 2019, Hlm. 1-6

Ahmad Efendi, Romy Talanipa: Evaluasi Waktu Menggunakan ...

\section{Pendahuluan}

Manajemen proyek dapat diartikan sebagai rangkaian kegiatan yang diawali dengan perencanaan, penjadwalan, pelaksanaan dan pengendalian untuk semuatahapan dalam proyek, dan diakhiri dengan selesainya sebuah proyek. Perencanaan proyek yang menyangkut seluruh faktor yang terkandung di dalam sebuah proyek, seperti waktu, biaya, pengalokasian tenaga kerja dan juga aktivitas-aktivitas.

Dinas Pekerjaan Umum (PU) Kabupaten Buton adalah instansi pemerintah yang betugas untuk melakukan pengawasan proyek pembangunan sarana dan prasarana. Metode umum yang digunakan dalam manajemen proyek di Kabupaten Buton, masih menggunakan metode konvensional, permasalahannya adalah hal ini sangat mempengaruhi waktu, biaya dan mutu pengerjaan proyek tersebut. Untuk itu perubahan manajemen proyek yang ada sangat diperlukan. Adapun proses manajemen yang perlu mengalami perubahan diantaranya adalah perencanaan, penjadwalan dan pengendalian proyek, hal ini bertujuan agar proyek yang dilaksanakan dapat berjalan sesuai dengan yang direncanakan.

Di dalam pelaksanaan pengerjaan proyek pembuatan jalan rabat beton di Desa Kamelanta Kecamatan Kapontori Kabupaten Buton terdapat beberapa aktivitas pekerjaan yang seharusnya dapat dikerjakan secara bersamaan namun hal tersebut tidak dilakukan sehingga efisisensi waktu dana biaya tidak terjadi. Seharusnya jika hal tersebut dilakukan maka akan terdapat efisiensi waktu aupun biaya dalam proses pengerjaannya. Berdasarkan deskripsi di atas, fokus penelitian adalah bagaimanakah pengendalian manajemen waktu pada proyek jalan rabat beton Desa Kamelanta Kecamatan Kapontori Kabupaten Buton menggunakan metode network CPM (Critical Path Method)?
Tujuan penelitian ini adalah untuk mengetahui pengendalian manajemen waktu pada proyek jalan rabat beton Desa Kamelanta Kecamatan Kapontori Kabupaten Buton menggunakan metode network CPM (Critical Path Method).

\section{Penelitian}

Objek penelitian yang dilakukan tentang waktu pelaksanaan proyek dan besarnya biaya proyek. Jenis data yang digunakan dalam penelitian ini adalah data primer dan data sekunder. Data yang digunakan adalah (1) Waktu penyelesaian proyek sebelum adanya percepatan dan waktu penyelesaian setelah adanya percepatan; (2) Data urutan rangkaian kegiatan proyek; (3) Data waktu dan biaya kegiatan proyek; dan (4) Data lain yang berhubungan dengan permasalahan penelitian.

Dalam menganalisis penelitian ini menggunakan langkah-langkah sebagai berikut (1) Menyusun hubungan ketergantungan antara aktivitas-aktivitas yang terlibat dalam pelaksanaan dan penyelesaian proyek dan menentukan waktu dan biaya normal dan dipercepat; (2) dan Membuat Diagram Network.

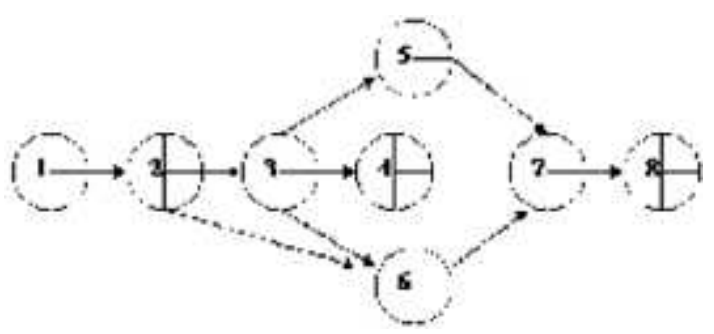

Gambar 1 Hubungan Ketergantungan (Yamit, 2000:295)

1. Menentukan saat paling cepat dan saat paling lambat dengan rumus :

$\mathrm{SPC} j=\operatorname{Max}(\mathrm{SPCi}+\mathrm{L})$

SPLi $=$ Min (SPLj - L)

2. Menentukan jalur kritis sebelum percepatan, dimana SPC = SPL . 


\section{SANG PENCERAH}

Volume 5, Nomor 1, Februari 2019, Hlm. 1-6

\section{Ahmad Efendi, Romy Talanipa: Evaluasi Waktu Menggunakan ...}

3. Melakukan percepatan proyek berdasarkan Diagram Network dengan CPM untuk percepatan waktu.

a. Membuat percepatan untuk percepatan setiap pekerjaan.

b. Mempercepat waktu penyelesaian proyek dengan mengutamakan kegiatan kritis yang memiliki kegiatan terkecil jika pada langkah kedua proyek tidak dapat dipercepat berarti telah ditemukan biaya minimum percepatan proyek maka proses berhenti.

c. Jika proyek masih memungkinkan untuk dipercepat maka susunlah kembali Network yang baru dengan menggunakan waktu kegiatan yang dipercepat yang masih memungkinkan untuk dipercepat sampai waktu maksimum dan menentukan SPCi, SPCj, SPLi, SPLj sesudah percepatan dan menentukan jalur kritis.

\section{Pembahasan}

\section{Analisis Jaringan Kerja}

Berdasarkan data lapangan, didapatkan uraian perkerjaan yang dilakukan dalam pelaksanaan pekerjaan proyek yang ditabelkan dalam tabel 1 di bawah ini.

\section{Tabel 1 Uraian Pekerjaan}

\begin{tabular}{lcc}
\hline \multicolumn{1}{c}{ Uraian Kegiatan } & $\begin{array}{c}\text { Durasi } \\
\mathbf{( M i n g g u})\end{array}$ & $\begin{array}{c}\text { Predece } \\
\text { ssor }\end{array}$ \\
\hline Pembersihan, Pengukuran \& & 1 & - \\
Pas.Bowplank & 7 & A \\
Administrasi, Dokumentasi dan P3K & 7 & A \\
Pengadaan Air Kerja & 1 & A \\
Embuatan Papan Nama Proyek & 1 & A \\
Galian Tanah & 4 & E \\
Pasangan Batu Gunung & 7 & E \\
Pasangan Batu Kosong & 6 & E \\
Urugan Batu 2/3 & 6 & E \\
Rabat Beton & 1 & F, G, H, I \\
Pembersihan Kembali & & \\
\hline
\end{tabular}

\section{Sumber: Data Sekunder}

Setelah menentukan uraian pekerjaan, selanjutnya dibuat jaringan kerja berdasarkan uraian kerja yang telah ditentukan yang diperlihatkan pada gambar 2 berikut ini.

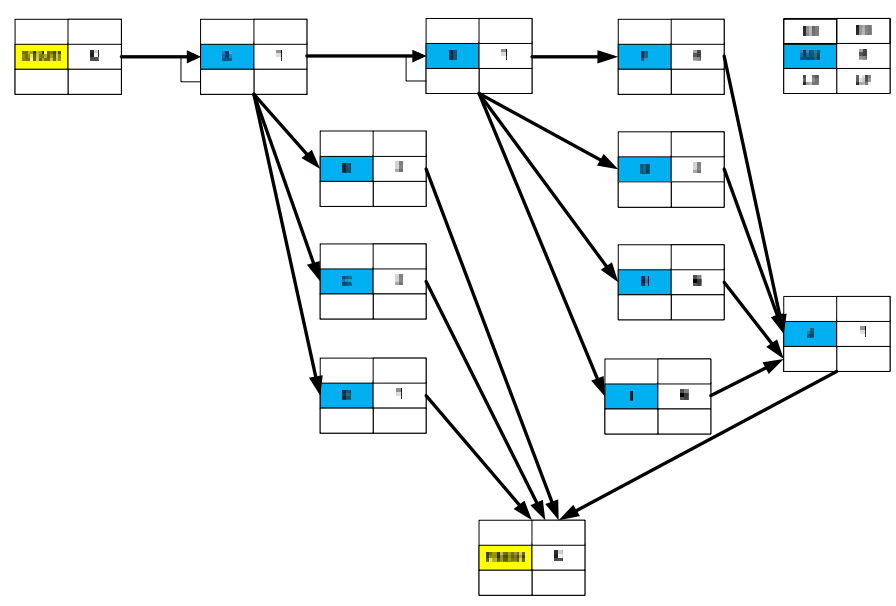

\section{Gambar 2 Diagram Jaringan Kerja}

Selanjutnya dilakukan perhitungan maju (forward pass), dimana perhitungan dimulai dari Start (initial event) menuju Finish (terminal event) untuk menghitung waktu penyelesaian tercepat suatu kegiatan (EF), waktu tercepat terjadinya kegiatan (ES) dan saat paling cepat dimulainya suatu peristiwa (E) dan melakukan perhitungan mundur (backward pass) dimulai dari Finish menuju start untuk mengidentifikasi saat paling lambat terjadinya suatu kegiatan (LF), waktu paling lambat terjadinya suatu kegiatan (LS) dan saat paling lambat suatu peristiwa terjadi (L). Hasil perhitungan maju da perhitungan mundur diperlihatkan pada gambar 3 di bawah ini. 


\section{SANG PENCERAH}

Volume 5, Nomor 1, Februari 2019, Hlm. 1-6

\section{Ahmad Efendi, Romy Talanipa: Evaluasi Waktu Menggunakan ...}

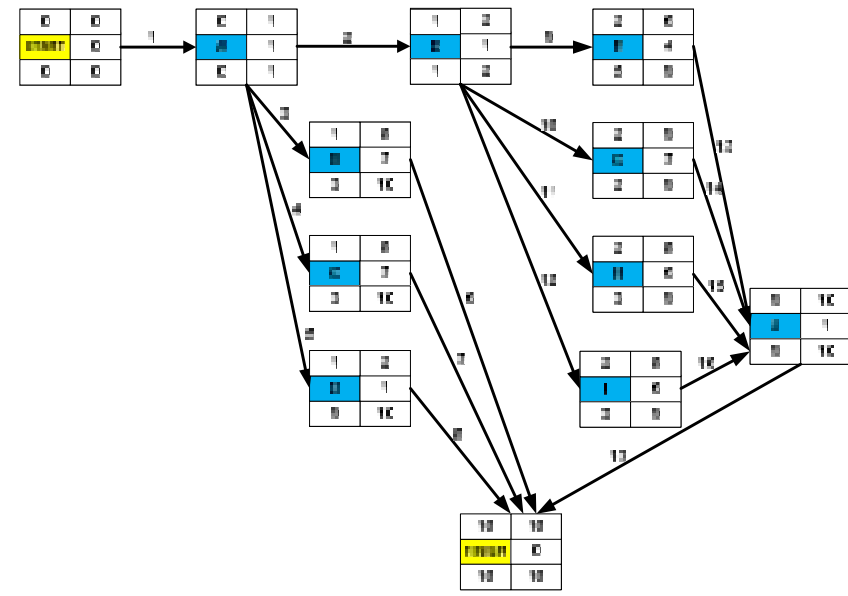

\section{Gambar 3 Penentuan Jalur, Perhitungan Maju dan Perhitungan Mundur}

Berdasarkan gambar 3 diatas, diketaui bahwa total waktu yang diperlukan untuk menyelesaikan proyek adalah 10 minggu dengan total 17 jalur.

\section{Penentuan Jalur Kritis}

Untuk mengetahui jenis pekerjaan yang bisa dan tidak bisa ditunda, terlebih dahulu harus ditentukan float dari masing masing aktivitas pekerjaan. Float adalah Jumlah waktu yang diijinkan dalam perlambatan suatu proyek dari waktu dimulainya tanpa memperlambat waktu akhir penyelesaian proyek keseluruhan. Perhitungan Float ditampilkan dalam tabel 2 berikut ini.

\section{Tabel 2 Perhitungan Float}

\begin{tabular}{|c|c|c|c|c|c|c|c|}
\hline Aktivitas & $\begin{array}{c}\text { Durasi } \\
\text { Pelaksanaan }\end{array}$ & ES & EF & LS & LF & FF (4-3-2) & TF (6-3-2) \\
\hline$(1)$ & $(2)$ & $(3)$ & $(4)$ & $(5)$ & $(6)$ & $(7)$ & $(8)$ \\
\hline A & 1 & 0 & 1 & 0 & 1 & 0 & 0 \\
B & 7 & 1 & 8 & 3 & 10 & 0 & 2 \\
C & 7 & 1 & 8 & 3 & 10 & 0 & 2 \\
D & 1 & 1 & 2 & 9 & 10 & 0 & 8 \\
E & 1 & 1 & 2 & 1 & 2 & 0 & 0 \\
F & 4 & 2 & 6 & 5 & 9 & 0 & 3 \\
G & 7 & 2 & 9 & 2 & 9 & 0 & 0 \\
H & 6 & 2 & 8 & 3 & 9 & 0 & 1 \\
I & 6 & 2 & 8 & 3 & 9 & 0 & 1 \\
J & 1 & 9 & 10 & 9 & 10 & 0 & 0 \\
\hline
\end{tabular}

Sumber: Pengolahan Data

Dari tabel diatas diperoleh 6 aktivitas pekerjaan yang dapat ditunda yaitu aktivitas
B (Administrasi, Dokumentasi dan P3K) dapat ditunda selama 2 minggu, aktivitas C (Pengadaan Air Kerja) dapat ditunda 2 minggu, aktivitas D (Pembuatan Papan Nama Proyek) dapat ditunda 8 minggu, aktivitas F (Pasangan Batu Gunung) dapat ditunda selama 3 minggu dan masingmasing aktivitas $\mathrm{H}$ (Urugan Batu 2/3) dan I (Rabat Beton) dapat ditunda pelaksanaannya selama 1 minggu.

Aktivitas-aktivitas dengan nilai total float adalah 0 adalah aktivitas kritis yang tidak bisa ditunda waktu pelaksanaanya yang terbentuk berdasarkan analisis CPM (Critical Path Method). Aktivitas kritis ini meliputi aktivitas A (Pembersihan, Pengukuran dan Pas.Bowplank), E (Galian Tanah), G (Pasangan Batu Kosong) dan J (Pembersihan Kembali) yang membentuk jalur kritis yaitu jalur 1-2-10-14-17 sebagaimana diperlihatkan pada gambar 4 di bawah ini.

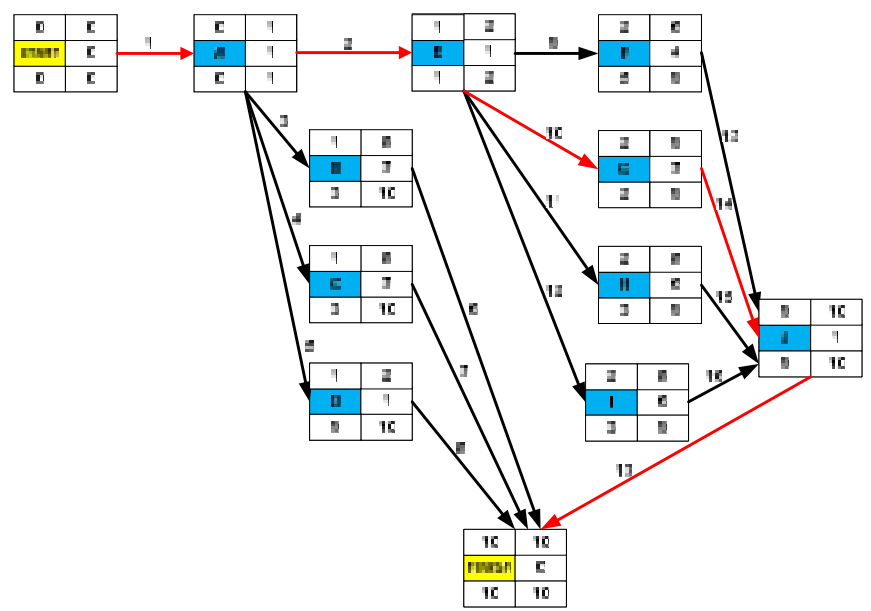

\section{Gambar 4 Jalur Kritis Proyek Rabat Beton}

\section{Evaluasi Waktu Proyek}

Setelah menentukan jalur kritis, selanjutnya akan dilakukan evaluasi waktu pelaksanaan proyek dengan menggunakan metode yang sama yaitu Critical Path Method $(C P M)$. Evaluasi ini dilakukan pada jalur kritis dalam rangka percepatan waktu penyelesaian proyek seperti tampak pada gambar 5, dimana jalur kritis yang terbentuk 


\section{SANG PENCERAH}

Volume 5, Nomor 1, Februari 2019, Hlm. 1-6

\section{Ahmad Efendi, Romy Talanipa: Evaluasi Waktu Menggunakan ...}

setelah evaluasi penyelesaian proyek adalah jalur 1-4- 12 - 15 dengan total waktu yang dibutuhkan untuk menyelesaikan proyek dari 10 minggu menjadi 9 minggu. Jika aktivitas E, F, G, H dan I dimulai setelah aktivitas A, maka aktivitas kritis akan berubah dari 4 aktivitas kritis menjadi 3 aktivitas kritis yaitu aktivitas A (Pembersihan, Pengukuran dan Pas.Bouwplank), G (Pasangan Batu Kosong) dan J (Pembersihan Kembali) karena aktivitas F,G, H dan I tidak bergantung pada waktu penyelesaian aktivitas E.

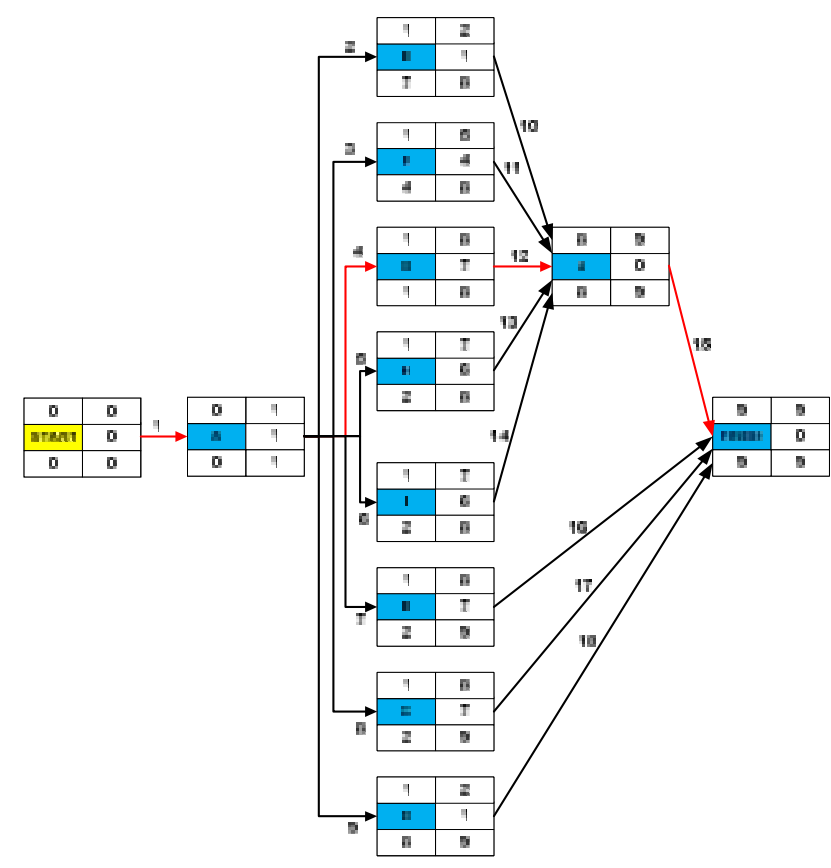

\section{Gambar 5 Jalur Kritis Evaluasi}

Perhitungan total float setelah evaluai ditampilkan dalam Tabel 3 berikut ini.

\begin{tabular}{|c|c|c|c|c|c|c|c|}
\hline Aktivitas & $\begin{array}{c}\text { Durasi } \\
\text { Pelaksanaan }\end{array}$ & ES & EF & LS & LF & FF (4-3-2) & TF (6-3-2) \\
\hline$(1)$ & $(2)$ & $(3)$ & $(4)$ & $(5)$ & $(6)$ & $(7)$ & $(8)$ \\
\hline A & 1 & 0 & 1 & 0 & 1 & 0 & 0 \\
B & 7 & 1 & 8 & 2 & 9 & 0 & 1 \\
C & 7 & 1 & 8 & 2 & 9 & 0 & 1 \\
D & 1 & 1 & 2 & 8 & 9 & 0 & 7 \\
E & 1 & 1 & 2 & 7 & 8 & 0 & 6 \\
F & 4 & 1 & 5 & 4 & 8 & 0 & 3 \\
G & 7 & 1 & 8 & 1 & 8 & 0 & 0 \\
H & 6 & 1 & 7 & 2 & 8 & 0 & 1 \\
I & 6 & 1 & 7 & 2 & 8 & 0 & 1 \\
J & 1 & 8 & 9 & 8 & 9 & 0 & 0 \\
\hline
\end{tabular}

Sumber: Pengolahan Data

Dari Tabel 3 diperoleh 7 aktivitas pekerjaan yang dapat ditunda yaitu aktivitas B (Administrasi, Dokumentasi dan P3K) dapat ditunda selama 1 minggu, aktivitas $C$ (Pengadaan Air Kerja) dapat ditunda 1 minggu, aktivitas D (Pembuatan Papan Nama Proyek) dapat ditunda 7 minggu, aktivitas E (Galian Tanah) dapat ditunda 6 minggu, aktivitas F (Pasangan Batu Gunung) dapat ditunda selama 3 minggu dan masingmasing aktivitas H (Urugan Batu 2/3) dan I (Rabat Beton) dapat ditunda pelaksanaannya selama 1 minggu.

\section{Simpulan}

Simpulan penelitian ini bahwa (1) Total waktu penyelesaian pekerjaan proyek Jalan Rabat Beton di Desa Kamelanta Kecamatan Kapontori Kabupaten Buton adalah 10 minggu yang menunjukkan manajemen waktu proyek ini tidak terganggu serta pekerjaan sudah berjalan dengan baik; (2) Dengan Menggunakan metode CPM (Critical Path Method), proyek jalan rabat beton Desa Kamelanta Kecamatan Kapontori Kabupaten Buton dapat dipercepat waktu penyelesaiannya menjadi 9 minggu dengan cara aktivitas $\mathrm{E}$ (Galian Tanah), F (Pas. Batu Gunung), G (Pas. Batu Kosong), H (Urugan Batu 2/3) dan I (Rabat Beton) waktu pekerjaannya dilaksanakan bersamaan, sehinggah jalur kritis yang akan terbentuk pada pekerjaan ini adalah jalur $1-4-12-15$. 


\section{SANG PENCERAH}

Volume 5, Nomor 1, Februari 2019, Hlm. 1-6

\section{Ahmad Efendi, Romy Talanipa: Evaluasi Waktu Menggunakan ...}

\section{Daftar Pustaka}

Arianti, 2002. “Skripsi Penerapan Diagram Network dengan CPM Dalam Efiensi Waktu dan Biaya Studi Kasus di Perusahaan Garmen Collection Malang". Universitas Malang.

Badiri, Sofwan, 1997. Dasar-Dasar Network Planning. Jakarta. Rineka Cipta.

Brabdib, Dick H. And Gray. Max. 1970. Project Control Standart. New York: Brandon/System Press Inc.

Clough, Richard H. And Sears, Glenn A. 1991. Costruction Project Management. Canada : John Willey \& Sons Inc.

Dimyati Tarliah T, Dimyati Ahmad. 1999. Operation Research Model-Model Pengambilan Keputusan. Bandung: Sinar Baru Algensindo.

Ervianto, Wulfram. 2004. Teori-Aplikasi Manajemen Proyek Konstruksi. Edisi 1. Yogyakarta: Andi.

Hayun, Anggara. 2005. Perencanaan Pengendalian Proyek dengan Metode PERT-CPM: Studi Kasus Fly Over Ahmad Yani, Karawang. Journal The Winner Vol. 6, No.2, h.155-174.

Heizer, Jay and Render, Barry. 2006. Operations Manageent. $8^{\text {th }}$ Edition. New Jersey: Pearson Education Inc. Prentice Hall.

Project Managemen Institute. 1996. A Guide to the Project Management Body of Knoledge (PMBOK). United States: PMI Pulications.

Sakdiah. 2004. "Skripsi Network Planning Dengan CPM Dalam Usaha Meningkatkan Efisiensi Biaya dan Waktu Pada Proyek Pembangunan
Perkantoran di PT Nilano Malang". Universitas Malang.

Sandhyavitri, A. And Young, R.J.,2004. Risk Management in Water Supply, 27 th of WEDC Conference, Vientien.

Soeharto, Imam. 1995. Manajemen Proyek : Dari Konseptual Sampai Operasional. Jakarta: Erlangga.

Soeharto, Imam. 1999. Manajemen Proyek: Dari Konseptual Sampai Operasional. Edisi 2, Cetakan 1. Jakarta : Erlangga.

Schroeder, Roger G. 2000. Operations Mangement: Contemporary Concepts and Cases, International Edition, Mc GrawHill Companies, Inc, Boston.

Smith, Karl A. 2000. Project Management and Teamwork. Minnesota: McGraw-Hill Inc.

Tim Penulis Dosen Jurusan Sipil Fakultas Teknik Universitas Diponegeoro, 2002. Modul Ajar Manajemen Konstruksi I, UPT Penerbitan Universitas Diponegeoro.

Yamit, Zulian. 2000. Manajemen Kualitas Produk dan Jasa. Jogjakarta: Penerbit Ekonosia. 